\title{
Risk factors for cardiomyopathy syndrome (CMS) in Norwegian salmon farming
}

\author{
Britt Bang Jensen ${ }^{1, *}$, Edgar Brun $^{1}$, Birgitte Fineid ${ }^{1}$, Rolf Bjerke Larssen ${ }^{2}$, \\ Anja B. Kristoffersen ${ }^{1,3}$ \\ ${ }^{1}$ Norwegian Veterinary Institute, Section for Epidemiology, 0106 Oslo, Norway \\ ${ }^{2}$ Norwegian School of Veterinary Science, Section for Production Animal Medicine, 0033 Oslo, Norway \\ ${ }^{3}$ Department of Informatics, University of Oslo, PO Box 1080, Blindern, 0316 Oslo, Norway
}

\begin{abstract}
Cardiomyopathy syndrome (CMS) has been an economically important disease in Norwegian aquaculture since the 1990s. In this study, data on monthly production characteristics and case registrations were combined in a cohort study and supplemented with a questionnairebased case-control survey on management factors in order to identify risk factors for CMS. The cohort study included cases and controls from 2005 to 2012. From this dataset differences between all cases and controls were analyzed by a mixed effect multivariate logistic regression. From this we found that the probability of CMS increased with increasing time in the sea, infection pressure, and cohort size, and that cohorts which had previously been diagnosed with heart and skeletal muscle inflammation or which were in farms with a history of CMS in previous cohorts had double the odds of developing CMS. The model was then used to calculate the predicted value for each cohort from which additional data were obtained via the questionnaire-based survey and used as offset for calculating the probability of CMS in a semi-univariate analysis of additional risk factors. Finally, the model was used to calculate the probability of developing CMS in 100 different scenarios in which the cohorts were subject to increasingly worse conditions with regards to the risk factors from the dataset. We believe that this exercise is a good way of communicating the findings to farmers, so they can make informed decisions when trying to avoid CMS in their fish cohorts.
\end{abstract}

KEY WORDS: Atlantic salmon · Salmo salar · Cardiomyopathy syndrome $\cdot$ Totiviridae $\cdot$ Piscine myocarditis virus $\cdot \mathrm{PMCV} \cdot$ Cohort study $\cdot$ Risk factor $\cdot$ CMS

\section{INTRODUCTION}

Cardiomyopathy syndrome (CMS) was first described in the 1980s in farmed Atlantic salmon Salmo salar in Norway (Amin \& Trasti 1988). The annual number of outbreaks increased steadily, and in 2001, 103 cases of CMS were registered at the Norwegian Veterinary Institute (NVI; Brun et al. 2003). Since 2004 , the annual number of cases has been between 49 and 89 (Fig. 1). A study from 2001 estimated the average losses from an outbreak of CMS on a fish farm with 260000 fish to be between $€ 120000$ and 187000 in 2001 value (Brun et al. 2003). These fig- ures are in line with recent losses estimated by Marine Harvest Norway. However, the actual losses per site will vary significantly (S. Øvretveit pers. comm.). The disease is not notifiable, but the NVI keeps records of all cases of CMS diagnosed at the NVI. In Norwegian aquaculture, CMS is only reported from farmed Atlantic salmon, whereas no cases have been reported from farmed rainbow trout Oncorhynchus mykiss, the second-largest farmed species in Nor-

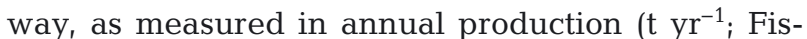
keridirektoratet 2012). CMS-like lesions have also been reported from wild Atlantic salmon (Poppe \& Seierstad 2003). 

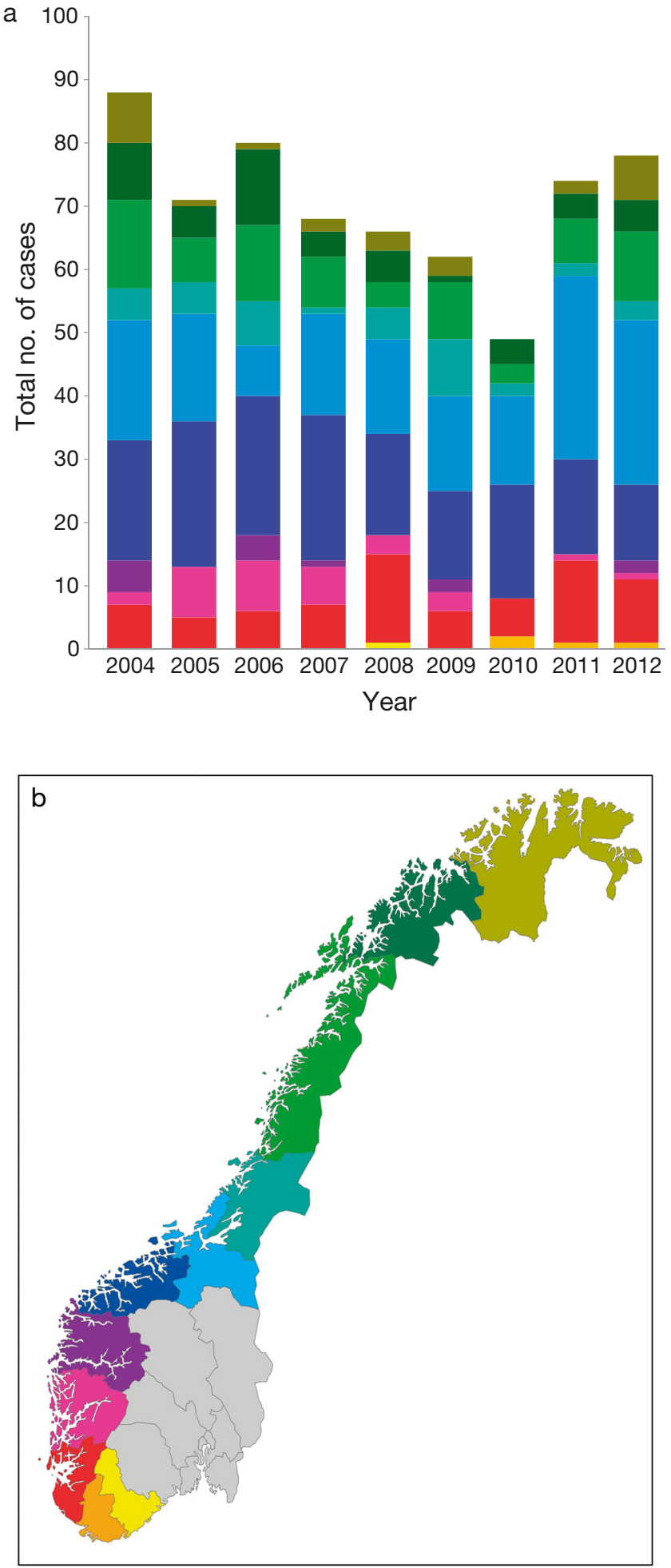

Fig. 1. (a) Yearly number of all cases of cardiomyopathy syndrome in farmed salmon Salmo salar between 2004 and 2012, divided among Norwegian counties. (b) Map shows the location of each county, with colors corresponding to the graph. Grey areas indicate countries with no salmonid fishing. (Data collected by the Norwegian Veterinary Institute)
The disease is characterized by chronic progressive inflammation in the tissues of the heart leading to necrosis and eventual functional failure of the heart and in some cases cardiac tamponade (Amin \& Trasti 1988, Ferguson et al. 1990). The etiology of the disease has long been unknown, even though it was expected to be of an infectious nature, but stress and/or hypoxia have also been proposed as necessary causes for the syndrome. Later years have shown a breakthrough in establishing the etiology of CMS: in 2009, 2 studies were published independently, both reporting successful experimental transmission of CMS in Atlantic salmon using tissue homogenates from fish collected during outbreaks of CMS in the field (Bruno \& Noguera 2009, Fritsvold et al. 2009). Subsequently, additional challenges have been performed where homogenates were filtered through $0.22 \mu \mathrm{m}$ filters before successfully transmitting CMS to healthy fish, indicating that the infectious agent is a virus (Timmerhaus et al. 2011). In 2010, a major breakthrough was achieved when 2 independent research groups both identified the causal agent for CMS, a hitherto unknown virus belonging to the family Totiviridae, which was subsequently named piscine myocarditis virus (PMCV). One group used high throughput sequencing to search for sequences from unknown viruses in field samples, whereas the other identified the virus through inoculation on cell culture and subsequently cloning and sequencing of virus particles (Løvoll et al. 2010, Haugland et al. 2011). Haugland et al. (2011) also succeeded in reproducing CMS in fish infected with the virus grown in cell culture, thereby establishing PMCV as the causal agent of CMS by fulfilling Koch's postulates. Since the identification of the infectious agent, PMCV has been found in wild Atlantic salmon and smelt Argentina silus (Böckerman et al. 2011, Garseth et al. 2012).

Now that the causal agent has been established, the lack of knowledge of potential risk factors for introduction of PMCV and outbreak of CMS has become even more evident. Thus, in the present study, our objective was to investigate important risk and indicator factors for CMS in Norwegian salmon farming.

\section{MATERIALS AND METHODS}

The study was designed as a combination of a cohort study, in which we analyzed data from official registers on monthly production characteristics and case registrations from the NVI, and a questionnaire- 
based case-control survey, in which we collected data on management factors from a subset of the cohort study population.

\section{Cohort study}

Study population and data source

Salmon farming consists of a freshwater phase of smolt production, followed by a marine grow-out phase. The marine production is conducted on certified farm sites authorized by the Directorate of Fisheries (DFF) and geo-referenced in the Aquaculture register (DFF; www.fiskeridir.no). The dominant practice for marine production is that farms are stocked with cohorts of salmon smolts, which are then grown at those farm sites until they are harvested. The farms are then fallowed for a period before stocking with a new cohort of smolts (see Kristoffersen et al. 2009). In the present study, only cohorts of Atlantic salmon that were transferred to marine waters after December 2004 and harvested or moved before January 2013, and that were held on the same farm for at least $6 \mathrm{mo}$, were included. Here we define a cohort as a group of fish put to sea at the same farm within a period of a few months. They might originate from different smolt suppliers but are always in the same year class.

All farms actively farming salmonids in marine waters must report key production statistics on a monthly basis to the authorities. These statistics include stock numbers of fish and average fish weight. The data were obtained for all cohorts included in the present study and pre-processed as described by Kristoffersen et al. (2009).

\section{CMS case definition}

A list of recorded CMS cases during 2004 to 2012 on identified farms, including the month when samples were received at the NVI, was compiled from the laboratory information system at the NVI. The list of cases included all cases in which histopathological findings were consistent with CMS, regardless of whether the overall conclusion from the case investigation was reported as suspected CMS or confirmed CMS. These cases all derived from samples that were sent to the NVI in order to investigate abnormal mortalities or other clinical disease signs.

It is not mandatory to report CMS, but abnormal mortalities in a fish cohort must be investigated to try to establish the cause (Fiskeri- og kystdepartementet 2008). CMS may therefore be identified in many samples submitted for diagnosis, regardless of what suspicions there might be towards the underlying cause of disease. Hence we believe that the list includes most of the CMS cases. Furthermore, all Norwegian aquaculture production sea sites are required by legislation to undergo clinical inspections by fish health services at least 6 times a year (Fiskeri- og kystdepartementet 2008). Therefore, any case of CMS that has not been reported by the farmer will most likely be discovered at these inspections.

Case cohorts were defined as cohorts with a CMS diagnosis (as described in the case definition above) during their marine grow-out phase, while control cohorts were defined as all other cohorts. The dataset included 1914 control cohorts and 371 case cohorts.

\section{Other diseases}

Lists of reported heart and skeletal muscle inflammation (HSMI), infectious pancreatic necrosis (IPN), and pancreas disease (PD) cases were retrieved by the NVI. HSMI is diagnosed the same way as CMS, and thus a similar case definition as for CMS was used for this disease. IPN and PD are diagnosed either by PCR or by histopathology. In this study, a case was defined as a diagnosis either by PCR or histopathology. Because we wanted to investigate whether having experienced any of these diseases in the cohort increased the probability of CMS, only disease occurrences prior to a CMS diagnosis were included.

\section{Infection pressure}

It was assumed that a susceptible cohort is exposed to CMS infection from all proximate cohorts in which there are infectious fish, dependent on the seaway distance between susceptible and infectious cohorts, $d_{i j}$. Calculation of seaway distance was described by Kristoffersen et al. (2009). Infection pressure was calculated based on the formula:

$$
i p_{i}(t)=I_{i}^{S}(t) \sum_{j \in N_{i}(t)} \frac{I_{j}^{I}(t) x_{j}(t)}{d_{i j}}
$$

where $i$ is the cohort for which the infection pressure $\left(i p_{i}\right)$ was calculated in month $t, I_{i}^{S}(t)$ is 1 if the fish in cohort $i$ are susceptible and 0 otherwise, $N_{i}(t)$ is all active cohorts within proximity of $i$ in month $t$, 
$I_{j}^{I}(t)$ is 1 if cohort $j$ was infectious at time $t$ and 0 if not. Since it is not known at which distance CMS is infectious, different levels of proximity were tested. The different levels of proximity used in the study were $5,10,25,50$, and $100 \mathrm{~km}$. Three different scenarios for the numerator $x_{j}(t)$ were tested: a constant term $_{i}$ the number of fish in cohort $j$ in month $t_{i}$ and the biomass of cohort $j$ in month $t$. A constant term in the numerator indicates that an infectious cohort in the neighborhood is important, independent of the size of the infected cohort. Accounting for the number of fish or biomass in the numerator indicated that cohort infectiousness is dependent on the size of the fish stock.

How long a cohort was assumed infectious $\left(I_{j}^{I}(t)\right)$ was tested in different scenarios. All scenarios assumed that fish were infectious 2 mo prior to CMS detection. However, since it is not known how long the fish are infectious after a CMS diagnosis, the following post diagnosis levels were explored in this study: $2 \mathrm{mo}, 6 \mathrm{mo}$, and the remaining lifespan of the cohorts.

Even though CMS has been observed more often in relatively large fish (Brun et al. 2003), it is not known whether susceptibility $\left(I_{i}^{S}(t)\right)$ to CMS infection varies with size or age of the fish. Therefore, different restrictions on the exposure to infection were explored. The cases were examined to be susceptible only for the last 3 mo before CMS detection or for the entire period from sea transfer to initial diagnosis. The controls were assumed to be susceptible throughout their entire cohort lifespan. The infection pressure used in the logistic regression was defined as the maximum for the cohort over the period the fish were assumed to be susceptible. CMS case data from 1 yr before the study period were used to initialize calculation of the infection pressure.

\section{Other variables tested}

Cohorts where split into spring smolt cohorts, autumn smolt cohorts, mixed cohorts, or relocated cohorts as described by Kristoffersen et al. (2009). If the fish in the cohort were larger than $250 \mathrm{~g}$ at the beginning of the production period, this cohort was considered to have been moved from another sea site (relocated), since fish are not normally kept in fresh water above this weight.

Cohort size was defined as the maximum number of fish in the cohort. Monthly biomass per cohort was calculated as average weight multiplied by the number of fish, and maximum biomass per cohort ob- tained. Weight of the smolt at sea transfer was extracted from the production statistics register and used as a proxy for robustness of the smolt. For each cohort, it was registered whether there had been a CMS case in previous cohorts on the same site. Finally, cohort lifespan was calculated as the number of months from sea-transfer to termination of the cohort.

\section{Statistical analysis}

Mixed effect multivariate logistic regression was used to explore differences between case and control cohorts. As shown in Fig. 1, the number of outbreaks varied between different counties, so county was included as a random effect in the analysis. A preanalysis was done using logistic regression in generalized additive models (GAMs) and splines allowing the relationships between the independent and the dependent variables to be non-linear (Hastie \& Tibshirani 1996). Variables that were found to have a nonlinear relation were transformed such that all variables ended up having a linear relation. Akaike's information criterion (AIC) comparison between the regression with a spline function, and the transformed variables was used to ensure that the transformation explained as much as the spline did. AIC was also used to compare the different infection pressure scenarios in a univariate logistic regression model for each scenario using GAM and spline function. The scenario with the lowest AIC value was used further in the multivariable mixed-effect analysis. Finally, all scenarios of infection pressure were tested with the selected model and a final model was obtained. Relocated cohorts were not included in the model, as we have no information on infection pressure, HSMI, PD, IPN, and CMS in previous cohorts from before the cohort was relocated, and we could not calculate the cohort lifespan, since we did not know the date of sea transfer. The relocated cohorts constituted 107 cases and 456 controls which were removed from the analysis, and thus in the analysis, 221 case and 1307 control cohorts were included. To compare the contribution from each variable in the final model, an analysis based on standardized variables was conducted, and the odds ratio (OR) for each variable was calculated.

Based on the final model, the probability of a CMS diagnosis was calculated for 100 different scenarios; for scenario $x$ (from 1 to 100), the $x$ quantiles of all included explanatory variables were used, and subsequently plotted for increasing values of $x$. 
To evaluate the proportion of variance accounted for by the random effect in the mixed effect models, an intraclass correlation coefficient (ICC) was calculated as variance of the random effect divided by the variance of the random effect plus the variance of the residuals (Stanish \& Taylor 1983).

To measure the accuracy of the model, area under the curve (AUC) of a receiver operating characteristic (ROC) curve was calculated. The ROC curve is a plot of the sensitivity versus (1 - specificity) for all thresholds (Mason \& Graham 2002).

\section{Case-control study}

\section{Study population}

In order to address other hypothetic risk factors for which data were not available from the registers mentioned above, a questionnaire-based casecontrol study was performed on a subset of the population used in the cohort study. For the case-control study, cases and controls were selected as follows:

Cases: A list of all cohorts with CMS diagnosis from March 2009 to June 2010 was retrieved from the laboratory information system of the NVI. This comprised 79 cohorts.

Controls: A list of all cohorts actively farming salmon in January 2009 was retrieved. This comprised 498 cohorts. Of these, 120 were selected randomly, and any cohorts with CMS were excluded. Any cohorts with broodstock were also excluded.

Owners of all of the selected cohorts were contacted and asked if they would want to participate in the survey and whether there were still fish from the cohort on site, since we wanted to take out samples for confirmation of the initial diagnosis (for the cases) or to make sure they did not have CMS even if it had not been reported (controls). The sampling was carried out as follows: From each control cohort, 30 fish, preferably moribund or newly deceased, were sampled from random pens. From each case cohort, 15 moribund/deceased fish and 10 clinically healthy fish were sampled from the pen where the initial CMS diagnosis was made. Organ material (kidney, heart, muscle, liver, and pancreas) was preserved in formalin and sent to the NVI for histopathological examination using the protocol described by Fritsvold et al. (2009). These samples were used in another study, and are only used here for confirmation of the diagnosis. In total, all identified case cohorts (79) and 88 control cohorts were selected to participate in the survey.

\section{Questionnaire}

The questionnaire consisted of 17 questions and was divided into 3 sections: how the facility was operated, health-related information, and data on fish stock.

According to Norwegian legislation, the level of environmental impact from a sea site should be measured during the time with highest load from fish production by performing a Matfiskanlegg-Overvåking-Modellering (MOM)-analysis (Standard Norge 2007 ) or the equivalent (Fiskeri- og kystdepartementet 2008). The MOM-analysis evaluates the benthic impact on the environment directly under the site and assigns the site a level from 1 to 4 , where $1=$ low impact, 2 = moderate impact, 3 = high impact, or 4 = overloaded. In the questionnaire, we asked for the level of the MOM-analysis.

The questionnaire was distributed by email to all participants included in the survey and were followed up by telephone and email. The survey was closed in July 2011, 1 yr after the last CMS diagnosis was included.

Nine of those cohorts originally classified as controls were diagnosed with CMS after returning the questionnaire. These were thus included in the case cohorts. In total, questionnaires were received from 45 case cohorts (57\%) and 34 control cohorts (43\%).

\section{Statistical analysis}

The model obtained from the cohort study was used to calculated a predicted value $(\hat{y})$ for all controls and cases in the case-control study. Based on information from the questionnaire on the origin of relocated cohorts, all variables included in the model from the cohort study were obtained based on both locations depending on when the fish had been where.

The $\hat{y}$ from the cohort study was included in a semi univariate logistic regression model estimating the probability of detecting CMS for each cohort in the case-control study. Each of the answers $\left(x_{j}\right)$ from the questionnaire was analyzed in a model where the predicted value $(\hat{y})$ for each cohort $(i)$ was estimated and used as an offset in a semi univariate logistic regression model of the probability $\left(p_{i}\right)$ of CMS detection.

$$
\operatorname{logit}\left(p_{i}\right)=a+\hat{y}_{i}+b x_{i j}
$$

All programming was done in the statistical programming environment R 2.14.1 (R Development Core Team 2011) 


\section{RESULTS}

\section{Descriptive statistics}

The annual number of CMS cases in the study period varied between 49 at the lowest in 2010 and 89 at the highest in 2012 (Fig. 1). Most cases were registered in central Norway, and the distribution of cases in counties was consistent throughout the whole period. The median time from transfer of fish to the sea phase to initial diagnosis of CMS was 16 mo (interquartile range: 13-19 mo, relocated cohorts excluded), and the median average weight of the fish in a cohort at the time of initial CMS diagnosis was $3.6 \mathrm{~kg}$ (interquartile range: $2.4-4.7 \mathrm{~kg}$ ). The median time from initial CMS diagnosis to harvest was 5 mo (interquartile range: $3-8 \mathrm{mo}$ ).

Table 1 shows all tested variables, their distribution within cases and controls from the cohort study and p-values from ANOVA comparison of a univariate mixed effect logistic regression with null model including only the random effect of county. Comparing AIC values from the univariate analysis showed that cohort lifespan was the best predictor of CMS cases, followed by CMS in the previous cohort, HSMI in same cohort, infection pressure, and cohort size (Table 1). The variables 'weight at sea transfer,' 'IPN in same cohort,' 'PD in same cohort,' and 'cohort type' were not significant in the univariate analysis.

\section{Model fitting}

Univariate logistic regressions with different infection pressure scenarios showed that when the fish were assumed to be susceptible from sea transfer until CMS diagnosis or harvest, and to be infectious from 2 mo before CMS detection and the rest of the time in sea, the proximity of sites that contributed to the infection pressure was best modeled when the maximum seaway distance was set to $100 \mathrm{~km}$. The numerator of the model was 1 , indicating that all infected locations contributed similarly, independent of the size of the infected site. Infection pressure and cohort lifespan both gave better AIC value when included as a spline in the model than when included linearly. The spline function was examined, and based on AIC comparison, infection pressure was modeled as a linear function which leveled off with infection pressure equal to 0.5 . The effect of cohort lifespan increased linearly until $24 \mathrm{mo}$, with no further increase in the probability of acquiring CMS by leaving the fish at sea even longer. The final model can be found in Table 2, where the ICC of the model was 0.22 . The AUC of the resulting model was 0.865 .

\section{Risk factors for CMS}

The risk factors that were significant for increasing the probability of CMS were (in order of significance,

Table 1. Descriptive statistics for the potential risk factor variables from the cohort study for Salmo salar cohorts with and without cardiomyopathy syndrome (CMS). Only spring and autumn cohorts are included $(\mathrm{N}=1528)$. The results of single variable mixed effect logistic regressions with county as random effect are summarized by p-value based on ANOVA comparison with a null model where only the random effect is included and Akaike's information criterion (AIC; the null model had an AIC of 944). For the continuous variables, the mean \pm SD (5 and $95 \%$ quartiles in parentheses) is given. IPN: infectious pancreatic necrosis; HSMI: heart and skeletal muscle inflammation; PD: pancreas disease

\begin{tabular}{|c|c|c|c|c|c|}
\hline Variable & Level & Control cohorts & Case cohorts & $\mathrm{p}$ & $\mathrm{AIC}$ \\
\hline Weight at sea transfer $(\mathrm{g})$ & Mean & $113 \pm 38(65,190)$ & $110 \pm 38(66,191)$ & 0.587 & 945 \\
\hline Cohort size $\left(10^{3}\right.$ fish $)$ & Mean & $745 \pm 425(184,1507)$ & $1002 \pm 529(182,1971)$ & $<0.001$ & 925 \\
\hline IPN in cohort & $\begin{array}{l}\text { No } \\
\text { Yes }\end{array}$ & $\begin{array}{l}838 \\
469\end{array}$ & $\begin{array}{l}111 \\
110\end{array}$ & 0.116 & 943 \\
\hline HSMI in cohort & $\begin{array}{l}\text { No } \\
\text { Yes }\end{array}$ & $\begin{array}{l}891 \\
416\end{array}$ & $\begin{array}{c}74 \\
147\end{array}$ & $<0.001$ & 907 \\
\hline $\mathrm{PD}$ in cohort & $\begin{array}{l}\text { No } \\
\text { Yes }\end{array}$ & $\begin{array}{l}977 \\
330\end{array}$ & $\begin{array}{c}186 \\
35\end{array}$ & 0.403 & 945 \\
\hline CMS in previous cohort & $\begin{array}{l}\text { No } \\
\text { Yes }\end{array}$ & $\begin{array}{l}1161 \\
146\end{array}$ & $\begin{array}{c}122 \\
99\end{array}$ & $<0.001$ & 877 \\
\hline Infection pressure $\left(\mathrm{km}^{-1}\right)$ & Mean & $0.158 \pm 0.158(0,0.5)$ & $0.336 \pm 0.177(0.023,0.5)$ & $<0.001$ & 908 \\
\hline Cohort lifespan (mo) & Mean & $18.00 \pm 4.82(8,24)$ & $20.89 \pm 2.57(16,24)$ & $<0.001$ & 827 \\
\hline Cohort type & $\begin{array}{l}\text { Spring smolt } \\
\text { Autumn smolt }\end{array}$ & $\begin{array}{l}799 \\
508\end{array}$ & $\begin{array}{c}139 \\
82\end{array}$ & 0.687 & 945 \\
\hline
\end{tabular}


Table 2. Parameter estimates and p-values from the multivariate mixed effect logistic regression with county as random effect, modeling the probability of an outbreak of cardiomyopathy syndrome (CMS). The odds ratio (OR) for each estimate is provided. The continuous variables were scaled to mean 0 and SD 1 , so that the OR corresponds to an increase of 1 unit change in the scaled variables. $\triangle \mathrm{AIC}$ is the increase in Akaike's information criterion (AIC) for the full model without that variable. The intraclass correlation coefficient was 0.216 .

HSMI: heart and skeletal muscle inflammation; CI: confidence interval

\begin{tabular}{|lccccr|}
\hline Variable & $\begin{array}{c}\text { Standardized } \\
\text { coefficient } \\
\text { estimate }\end{array}$ & SE & p & $\begin{array}{c}\text { OR } \\
(95 \% \mathrm{CI})\end{array}$ & $\Delta$ AIC \\
\hline Intercept & -3.01 & 0.24 & $<0.001$ & & \\
Cohort lifespan & 1.16 & 0.15 & $<0.001$ & $3.20(2.40,4.28)$ & 95 \\
Infection pressure & 0.60 & 0.11 & $<0.001$ & $1.82(1.46,2.25)$ & 19 \\
Cohort size & 0.18 & 0.09 & 0.032 & $1.20(1.02,1.42)$ & 3 \\
HSMI in cohort & 0.70 & 0.19 & $<0.001$ & $2.00(1.37,2.93)$ & 11 \\
CMS in previous cohort & 0.82 & 0.20 & $<0.001$ & $2.27(1.54,3.34)$ & 14 \\
\hline
\end{tabular}

probability of CMS detection increased from 50.5 to $75.2 \%$.

Finally, the calculated predicted value $\hat{y}$ from the model was used for each cohort as an offset for calculating the probability of CMS in a semiunivariate analysis of the risk and indicator factors included in the casecontrol study. The responses from cases and controls in the questionnaire survey are presented in Table 3. The number of replies to each question varied between 21 and 42 for the cases and between 6 and 34 for the controls, since not every respondent answered all questions.

For one relocated cohort, it was not possible to trace the fish back to their

based on the OR): cohort lifespan, CMS in previous cohorts, HSMI in the same cohort, infection pressure, and cohort size (Table 2). The continuous variables 'infection pressure,' 'cohort lifespan,' and 'cohort size' were scaled to a mean of 0 and SD of 1 before inclusion in the model, so that the OR corresponds to an increase of 1 unit change in the scaled variables, or an increase of $1 \mathrm{SD}$ for the unscaled variables. For example, the OR of experiencing CMS is 1.82 (95\% CI: 1.46-2.25) if the infection pressure increases by $1 \mathrm{SD}$ (0.17). The variables 'weight at sea transfer' and 'IPN or PD in cohort' did not have a significant effect in the multivariate mixed effect logistic regression.

The resulting model was used to calculate the predicted probability of a CMS diagnosis for 100 different scenarios in which the cohorts had increasingly worse conditions with regards to the risk factors from the dataset. For each scenario, the $x$ quantile of infection pressure, cohort lifespan, and cohort size were used. The different scenarios were then sorted from 1 to 100 , where Scenario 1 had the best possible conditions with regards to development of CMS and Scenario 100 had the worst (Fig. 2). According to the cohort dataset, $63 \%$ of the cohorts did not detect HSMI; hence, the first 63 scenarios assumed that the cohort had not previously experienced HSMI while the following 37 scenarios assumed HSMI infection. Similarly, the first 84 scenarios assumed that the site had no history of CMS while the last 16 scenarios had experienced CMS in previous cohorts. More than $60 \%$ of the cohorts had less than $10 \%$ risk of getting CMS. When HSMI in same cohort was introduced, the predicted probability of CMS detection increased from 8.5 to $17.0 \%$, and similarly, when CMS in previous cohorts at the same site was added, the predicted origin, so it was excluded from the study. Another cohort consisted of broodstock fish, which can come from multiple other locations, so this cohort was also excluded. The final numbers of case and control cohorts included were 43 and 34, respectively. The only statistically significant risk or indicator factor for developing CMS was the use of oxygen logging, which was associated with a higher probability of developing CMS.

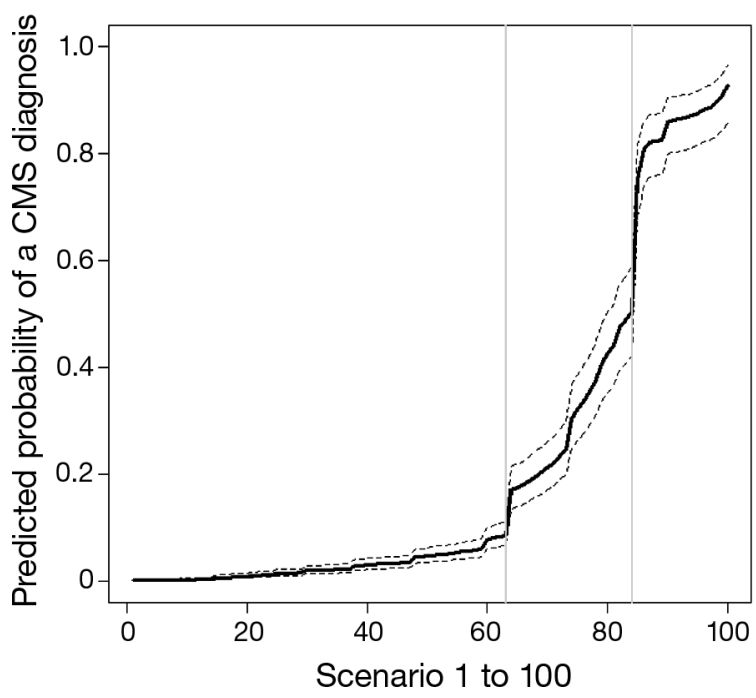

Fig. 2. Predicted probability of developing cardiomyopathy syndrome (CMS) based on the resulting model for 100 scenarios for cohorts with increasingly worse conditions for all predictor variables in the model. Dashed lines depict the $95 \%$ confidence interval. First vertical line marks the transition from cohorts that had no previous diagnosis of heart and skeletal muscle inflammation to cohorts that did. The second vertical line marks the transition from cohorts on sites with no CMS history to those on sites with CMS history 
Table 3. Original questions and replies from the survey performed in the casecontrol study. P-values are calculated as a comparison between cases and controls in a semi-univariate logistic regression model, including the predicted value $(\hat{y})$ from the cohort study. MOM: Matfiskanlegg-Overvåking-Modellering

\begin{tabular}{|c|c|c|c|c|}
\hline Original question: & Level & $\begin{array}{l}\text { Control } \\
\text { cohorts }\end{array}$ & $\begin{array}{l}\text { Case } \\
\text { cohorts }\end{array}$ & $\mathrm{p}$ \\
\hline What kind of construction is the site? & $\begin{array}{l}\text { Polarcirkel } \\
\text { Steel }\end{array}$ & $\begin{array}{c}5 \\
24\end{array}$ & $\begin{array}{l}11 \\
29\end{array}$ & 0.126 \\
\hline $\begin{array}{l}\text { Was the site fallowed before this } \\
\text { cohort was put to sea? }\end{array}$ & $\begin{array}{l}\text { No } \\
\text { Yes }\end{array}$ & $\begin{array}{c}2 \\
31\end{array}$ & $\begin{array}{c}4 \\
37\end{array}$ & 0.673 \\
\hline $\begin{array}{l}\text { Has there been synchronized } \\
\text { fallowing with neighboring sites? }\end{array}$ & $\begin{array}{l}\text { No } \\
\text { Yes }\end{array}$ & $\begin{array}{l}20 \\
14\end{array}$ & $\begin{array}{l}28 \\
12\end{array}$ & 0.409 \\
\hline Does the site collaborate with other sites? & $\begin{array}{ll}\text { No } & \text { Nos }\end{array}$ & $\begin{array}{l}13 \\
18\end{array}$ & $\begin{array}{l}20 \\
19\end{array}$ & 0.914 \\
\hline $\begin{array}{l}\text { Has a wellboat been used for sorting } \\
\text { or for lice-treatment during } \\
\text { the production period? }\end{array}$ & $\begin{array}{l}\text { No } \\
\text { Yes }\end{array}$ & $\begin{array}{l}22 \\
11\end{array}$ & $\begin{array}{l}12 \\
29\end{array}$ & 0.418 \\
\hline Does the site have oxygen logging? & $\begin{array}{l}\text { No } \\
\text { Yes }\end{array}$ & $\begin{array}{c}25 \\
7\end{array}$ & $\begin{array}{l}17 \\
24\end{array}$ & 0.048 \\
\hline Is water salinity measured? & $\begin{array}{l}\text { No } \\
\text { Yes }\end{array}$ & $\begin{array}{c}27 \\
5\end{array}$ & $\begin{array}{c}35 \\
5\end{array}$ & 0.411 \\
\hline Feeding regime on the site & $\begin{array}{c}\text { Continuously } \\
\text { As meals }\end{array}$ & $\begin{array}{l}\text { Y } 15 \\
17\end{array}$ & $\begin{array}{l}18 \\
24\end{array}$ & 0.686 \\
\hline $\begin{array}{l}\text { What level of environmental impact } \\
\text { did the site receive during the } \\
\text { MOM-analysis? }\end{array}$ & $\begin{array}{r}1 \\
>1\end{array}$ & $\begin{array}{l}17 \\
12\end{array}$ & $\begin{array}{l}25 \\
10\end{array}$ & 0.538 \\
\hline Stress on the site: Sorting? & $\begin{array}{l}\text { No } \\
\text { Yes }\end{array}$ & $\begin{array}{l}4 \\
8\end{array}$ & $\begin{array}{l}12 \\
25\end{array}$ & 0.550 \\
\hline Stress on the site: Flushing of nets? & $\begin{array}{l}\text { No } \\
\text { Yes }\end{array}$ & $\begin{array}{c}0 \\
11\end{array}$ & $\begin{array}{c}1 \\
37\end{array}$ & 0.995 \\
\hline Stress on the site: Problems with algae? & $\begin{array}{l}\text { No } \\
\text { Yes }\end{array}$ & $\begin{array}{l}4 \\
2\end{array}$ & $\begin{array}{c}25 \\
1\end{array}$ & 0.228 \\
\hline Stress on the site: Bad weather? & $\begin{array}{l}\text { No } \\
\text { Yes }\end{array}$ & $\begin{array}{l}3 \\
3\end{array}$ & $\begin{array}{c}12 \\
9\end{array}$ & 0.368 \\
\hline $\begin{array}{l}\text { Stress on the site: De-lousing by } \\
\text { bath treatment? }\end{array}$ & $\begin{array}{l}\text { No } \\
\text { Yes }\end{array}$ & $\begin{array}{c}1 \\
20\end{array}$ & $\begin{array}{c}0 \\
39\end{array}$ & 0.995 \\
\hline
\end{tabular}

The multivariate model was also applied to the relocated cohorts (107 cases and 456 controls), including the same variables except cohort lifespan. The same variables were found to be significant, and the ORs were comparable (within the $95 \%$ CI of the model); however, the order of significance changed a little: HSMI in cohort (OR: 2.24), infection pressure (OR: 1.85), CMS in previous cohort (OR: 1.82), and cohort size (OR: 1.47).

\section{DISCUSSION}

In this study, we identified important risk factors for CMS in Norwegian salmon farming. The probability of acquiring CMS increases with increasing cohort size and infection pressure. The risk of CMS also increases the longer the fish are in the sea and if they have previously experienced HSMI, or if the farm has a history of CMS in previous cohorts. We have also demonstrated that the use of oxygen logging in a farm can be an indicator that the farm has a higher risk of developing CMS.

The fact that the probability of CMS increases with the length of time in the sea is not surprising, as it reflects the fact that CMS is a progressively developing chronic disease. Thus, those cohorts with the longest lifespan have a higher probability of developing clinical CMS. We found that the median time between sea transfer and initial diagnosis was between 13 and 19 mo, which corresponds with findings by Brun et al. (2003), who reported that the average time between sea transfer and initial diagnosis was $410 \mathrm{~d}$ (13.6 mo).

The second most important risk factor for CMS was whether the cohort was on a farm with a history of CMS outbreaks in previous cohorts. Such cohorts had more than double the odds of developing CMS. This may reflect either 1 or a combination of 3 factors: some local environmental factor that is continuously present and is beneficial for the development of $\mathrm{CMS}_{\text {; }}$ factor relating to the management of the farm; or the survival of the causal agent of CMS in the immediate surroundings. The data from the cohort study were not suitable for investigating any of these factors, which was why a questionnaire-based survey was conducted. In this survey, we found that the use of oxygen logging in a farm was associated with a higher probability of acquiring CMS. Logging as such does not increase the risk of developing CMS, but the fact that some farms use oxygen logging is likely an indicator that these farms have (previous) experience with unstable oxygen levels in the water. It has often been suggested that hypoxia is involved in the development of CMS by minimizing the supply of oxygen to the already strained heart muscular tissue in CMS-affected fish (Bruno \& Noguera 2009). It is difficult to test the effect of hypoxia under field conditions, as farmers often use different protocols for measuring oxygen, and oxygen levels vary greatly, even within a cage, due to currents and clus- 
tering of the fish. However, a new research project will be testing the effect of different oxygen levels on the development of CMS under experimental conditions.

From our survey, we were unable to identify any statistically significant associations between management or environmental factors and CMS. This is probably due to too few observations, which made the dataset to be analyzed too small, with correspondingly low power. The fact that we decided to take samples for confirmation of CMS status in each cohort included in the study was a major constraint to how many cohorts could be included, as the sampling of sites is very costly. Further, some of the farmers had already harvested their stock when we contacted them, and thus the diagnosis could not be confirmed. At the time of the survey, the causal agent for CMS had not yet been identified, and extensive sampling and histopathological examination of the cohorts were necessary in order to secure the correct classification into cases and controls. Since the discovery of the agent, however, private companies offer screening for $\mathrm{PMCV}$, and it is anticipated that results from such screening programs can be used in future projects with the aim to establish causes of CMS.

The validity of the results from the case control dataset may be questioned due to the low response rate among cases (57\%) and controls (43\%). The low response rate makes them both less representative and increases the risk for selection error, which can falsely both introduce as well as hide associations. However, the cohort dataset includes practically all cohorts in the study period. Thus, the findings from the cohort dataset will be highly representative even though the causality of the associations may still be questioned.

We have developed a novel approach, wherein we used the model including data from the cohort dataset (the entire population at risk) to calculate a probability of CMS for each cohort included from a subset of the population for which we had more detailed information (the case-control study dataset), thereby getting the most information out of the data available. Since the case-control dataset was rather small, it could not be used for testing different risk factors in a multivariate analysis. However, by using the offset values calculated from the cohort dataset, we were able to take into account more risk factors in this study, thereby reducing the effects of uncontrolled biases.

The odds of developing CMS almost doubled with an increase of $1 \mathrm{SD}$ for infection pressure. We have used the model for calculating infection pressure for other viral diseases common in Norwegian aquaculture, and it has persistently proven to be well suited for capturing the effect of having neighboring sites infected with viral disease, adjusted by the number of such sites and the individual sea-way distance to these (Kristoffersen et al. 2009, 2013, Bang Jensen et al. 2012). The effect of infection pressure is to some extent area-dependent, as the infection pressure in areas with a high prevalence of CMS will naturally be high. However, by including county as a random variable, the model has already taken into account the fact that some counties have a much higher prevalence than others. Many reasons could explain such differences in prevalence between counties, including different management strategies, different practices for reporting disease, differences in sea temperature, or the presence of an unknown reservoir.

Given that the farmed fish share the same environment as wild fish, investigating whether wild fish could act as reservoirs has been a priority. However, after only finding PMCV in 2 of 797 wild salmon sampled from fjords all over Norway, Garseth et al. (2012) concluded that no strong link exists between PMCV in wild and farmed salmon. The isolate found in smelt was subsequently shown to be a genotype distinct from the one in salmon (Tengs \& Böckerman 2012), which together with the absence of PMCV in the other wild fish species tested makes it less likely that wild fish play an important role as a reservoir for PMCV.

In our study, the odds of getting CMS doubled if the cohort had previously been diagnosed with HSMI. A causal relationship between these 2 diseases has often been suggested, as they both affect the heart musculature, and recently, co-infections with PMCV and the virus associated with HSMI, piscine reovirus, have been observed (Løvoll et al. 2010, Wiik-Nielsen et al. 2012). Our results thus statistically confirm that HSMI is indeed a risk factor for CMS in farmed Atlantic salmon.

We used our model to predict the probability of CMS given 100 different scenarios, based on the dataset and the identified risk factors. We believe that this is a novel approach to illustrate the calculated risks to farmers. Fig. 2 shows that most of the cohorts actually have a low risk of developing CMS, because even the cohorts from the median of the dataset had a risk below $5 \%$ of developing CMS, and the cohorts with the best conditions had $<0.5 \%$ risk. However, large cohorts with long life spans, high infection pressure, a history of CMS, and previous 
HSMI diagnosis have less than $20 \%$ chance of not developing CMS. The figure also shows the effect of the 2 categorical risk factors (previous HSMI diagnosis and a history of CMS on site), as the risk increased dramatically for all scenarios where these 2 risk factors were present. When considering this figure, the very narrow confidence interval might be to some extent misleading, as it gives the impression that the results are very solid, whereas there might actually be some systematic errors that are not detectable. The confidence interval is narrow due to a relatively large dataset.

However, we believe that this approach is very useful when communicating the findings from our risk factor study to farmers, as it is very intuitive and can be used to pinpoint specific preventive measures towards reducing CMS in Norwegian salmon farming.

Acknowledgements. The study was financed by the Research Council of Norway, The Fishery and Aquaculture Industry Research Fund, and industrial partners (grant no. $187301 / \mathrm{s} 40$ ). We thank all farmers who took time to reply to the questionnaire and members of the project group for valuable discussions and suggestions.

\section{LITERATURE CITED}

Amin AB, Trasti J (1988) Endomyocarditis in Atlantic salmon in Norwegian sea farms. Bull Eur Assoc Fish Pathol 8: 70-71

Bang Jensen B, Kristoffersen AB, Myr C, Brun E (2012) Cohort study of effect of vaccination on pancreas disease in Norwegian salmon aquaculture. Dis Aquat Org 102: 23-31

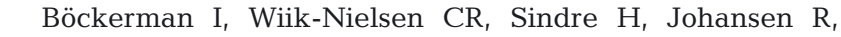
Tengs T (2011) Prevalence of piscine myocarditis virus (PMCV) in marine fish species. J Fish Dis 34:955-957

Brun E, Poppe T, Skrudland A, Jarp J (2003) Cardiomyopathy syndrome in farmed Atlantic salmon Salmo salar: occurrence and direct financial losses for Norwegian aquaculture. Dis Aquat Org 56:241-247

Bruno DW, Noguera PA (2009) Comparative experimental transmission of cardiomyopathy syndrome (CMS) in Atlantic salmon Salmo salar. Dis Aquat Org 87:235-242

Ferguson HW, Poppe T, Speare DJ (1990) Cardiomyopathy in farmed Norwegian salmon. Dis Aquat Org 8:225-231

Fiskeridirektoratet (2012) Key figures from the Norwegian aquaculture industry in 2011. Available at www. fiskeridir.no/fiskeridir/statistikk/akvakultur/statistiskepublikasjoner/noekkeltall-fra-norsk-havbruksnaering

Editorial responsibility: Mark Crane, Geelong, Victoria, Australia
Fiskeri- og kystdepartementet (2008) FOR 2008-06-17 nr 822. Forskrift om drift av akvakulturanlegg. Available at www.lovdata.no/cgi-wift/ldles?doc=/sf/sf/sf-200806170822.html

> Fritsvold C, Kongtorp RT, Taksdal T, Ørpetveit I, Heum M, Poppe TT (2009) Experimental transmission of cardiomyopathy syndrome (CMS) in Atlantic salmon Salmo salar. Dis Aquat Org 87:225-234

> Garseth ÅH, Biering E, Tengs T (2012) Piscine myocarditis virus (PMCV) in wild Atlantic salmon Salmo salar. Dis Aquat Org 102:157-161

Hastie TJ, Tibshirani RJ (1996) Generalized additive models. Chapman \& Hall, London

Haugland Ø, Mikalsen AB, Nilsen P, Lindmo K and others (2011) Cardiomyopathy syndrome of Atlantic salmon (Salmo salar L.) is caused by a double-stranded RNA virus of the Totiviridae family. J Virol 85:5275-5286

Kristoffersen AB, Viljugrein H, Kongtorp RT, Brun E, Jansen PA (2009) Risk factors for pancreas disease (PD) outbreaks in farmed Atlantic salmon and rainbow trout in Norway during 2003-2007. Prev Vet Med 90:127-136

> Kristoffersen AB, Bang Jensen B, Jansen PA (2013) Risk mapping of heart and skeletal muscle inflammation in salmon farming. Prev Vet Med 109:136-143

> Løvoll M, Wiik-Nielsen J, Grove S, Wiik-Nielsen CR and others (2010) A novel totivirus and piscine reovirus (PRV) in Atlantic salmon (Salmo salar) with cardiomyopathy syndrome (CMS). Virol J 7:309

Mason SJ, Graham NE (2002) Areas beneath the relative operating characteristics (ROC) and relative operating levels (ROL) curves: statistical significance and interpretation. Q J R Meteorol Soc 128:2145-2166

> Poppe TT, Seierstad SL (2003) First description of cardiomyopathy syndrome (CMS)-related lesions in wild Atlantic salmon Salmo salar in Norway. Dis Aquat Org 56:87-88

R Development Core Team (2011) R: a language and environment for statistical computing. R Foundation for Statistical Computing, Vienna

Standard Norge (Standards Norway) (2007) Environmental monitoring of benthic impact from marine fish farms. ICS 13.020; 65.150. Standard Norge, Lysaker

Stanish WM, Taylor N (1983) Estimation of the intraclass correlation coefficient for the analysis of covariance model. Am Stat 37:221-224

> Tengs T, Böckerman I (2012) A strain of piscine myocarditis virus infecting Atlantic argentine, Argentina silus (Ascanius). J Fish Dis 35:545-547

> Timmerhaus G, Krasnov A, Nilsen P, Alarcon M and others (2011) Transcriptome profiling of immune responses to cardiomyopathy syndrome (CMS) in Atlantic salmon. BMC Genomics 12:459

Wiik-Nielsen CR, Ski PMR, Aunsmo A, Løvoll M (2012) Prevalence of viral RNA from piscine reovirus and piscine myocarditis virus in Atlantic salmon, Salmo salar L., broodfish and progeny. J Fish Dis 35:169-171

Submitted: May 15, 2013; Accepted: October 2, 2013

Proofs received from author(s): December 2, 2013 